\title{
Botulinum Toxin as Preventive Treatment for Migraine: A Randomized Double-Blind Study
}

\author{
Susanne Petri ${ }^{a}$ Thomas Tölle ${ }^{b}$ Andreas Straube ${ }^{c}$ Volker Pfaffenrath $^{d}$ \\ Ulrich Stefenellie Andres Ceballos-Baumann ${ }^{f}$ \\ on behalf of the Dysport ${ }^{\circledR}$ Migraine Study Group \\ ${ }^{a}$ Department of Neurology, Medizinische Hochschule, Hannover, ${ }^{b}$ Department of Neurology, \\ Technische Universität, ' Department of Neurology, Ludwig-Maximilians-Universität, and d Neurological Practice, \\ Munich, ${ }^{e}$ Institute for Statistics, Würzburg, and fDepartment of Neurology and Clinical Neurophysiology, \\ Neurologisches Krankenhaus, Munich, Germany
}

\section{Key Words}

Botulinum toxin type $A \cdot$ Dysport $^{\circledR} \cdot$ Migraine $\cdot$

Randomized controlled trial rate with verum but did not show any statistically significant efficacy of BoNT-A in the prophylactic treatment of migraine.

Copyright $\odot 2009$ S. Karger AG, Basel

\begin{abstract}
Aim: To determine if botulinum toxin type A (BoNT-A) injections can reduce the frequency and severity of migraines. Methods: Patients $(n=127)$ were randomized to receive placebo or two doses of BoNT-A (Dysport ${ }^{\circledR}$ ). The primary endpoint was reduction in number of migraine attacks up to week 8 and between weeks 8 and 12 after injection. Patient diaries were used to record secondary endpoints, including frequency, severity and duration of migraine attacks. $\boldsymbol{R e}$ sults: There was a mean reduction of 0.54 and 0.94 attacks/ month with placebo and BoNT-A, respectively, and absolute attack count was less in the verum group (3.6 vs. 4.2 attacks/ month), but this was not statistically significant. The patients' global assessment of efficacy was significantly better than placebo in the high-dose group ( $p=0.02$ ) but no effects were seen for the other secondary efficacy parameters. Conclusion: Our study showed a trend towards a reduced attack
\end{abstract}

\section{Introduction}

Botulinum toxin type A (BoNT-A) is a potent neurotoxin that has been used for more than 20 years to treat a variety of syndromes associated with elevated tension of striated or smooth muscles, including focal dystonias, spasticity and achalasia [1-3]. BoNT-A reversibly inhibits release of acetylcholine at neuromuscular junctions, leading to a reduction in muscle tone and subsequent alleviation of painful muscle spasms. Its beneficial effects in hyperhidrosis show that it also acts on peripheral acetylcholinergic neurons [4].

Several studies have suggested that BoNT-A may be effective in the treatment of tension-type headache and migraine [5, 6]. Migraine is an episodic neurovascular disorder with a global prevalence of $4-9 \%$ in men and

\section{KARGER}

Fax +4161306 1234 E-Mail karger@karger.ch www.karger.com (c) 2009 S. Karger AG, Basel

0014-3022/09/0624-0204\$26.00/0

Accessible online at:

www.karger.com/ene
Susanne Petri, MD

Department of Neurology, Medizinische Hochschule

Carl-Neuberg Strasse 1, DE-30625 Hannover (Germany)

Tel. +49 511532 3740, Fax +49 5115323115

E-Mail petri.susanne@mh-hannover.de 
$11-25 \%$ in women [7]. According to the criteria of the International Headache Society (IHS), migraine is characterized by severe, mostly unilateral headache attacks with duration of 4-72 h, of pulsating quality, moderate-to-severe intensity, aggravated by routine physical activity and often associated with autonomic dysfunction and gastrointestinal symptoms $[8,9]$. Headaches can be preceded by a migraine aura, which is a complex of neurological symptoms that often present as temporary visual and/or sensory dysfunctions.

There are many (published and unpublished) case reports from patients who describe migraine improvement after treatment with BoNT-A for cosmetic purposes and who, after this positive experience, ask for repeat treatment [10]. To date, conflicting data have been obtained from clinical studies of BoNT-A for prophylactic treatment of migraine. Most of the open-label studies have shown that BoNT-A has good efficacy in migraine therapy, using either individualized or standardized protocols [11-13]. In all but one placebo-controlled prospective study [14], however, BoNT-A did not show any statistically significant superiority in reducing migraine frequency or severity compared with placebo [15-19]. A positive evidence for treatment with botulinum toxin in headache disorders remains to be proven up to date [20].

To further investigate whether a standardized, prophylactic scheme of BoNT-A injections can reduce the frequency and severity of migraine and associated symptoms, we conducted a prospective, multicenter, randomized, double-blind, placebo-controlled trial of a highly purified Clostridium botulinum type A toxin-hemagglutinin complex (Dysport ${ }^{\circledR}$; Ipsen Ltd., Slough, UK) administered during a single treatment session into cervical and/or pericranial muscles.

\section{Patients and Methods}

\section{Patients}

Men and women between 18 and 65 years of age were included in the study if they had at least a 1-year history of migraine with or without aura, a first manifestation under 50 years of age, and a stable frequency of 3-6 attacks per month according to IHS 1988 criteria (the most recent criteria available at the time of the study) [8]. Patients had not previously received BoNT-A, and no concomitant prophylactic migraine treatment was allowed during the study. Acute medication for migraine was allowed for a maximum of 10 days per month, although patients were restricted to only one type of escape medication that they preferably used (either analgesic or triptan). Patients who experienced non-migraine headaches for more than 10 days per month before, but not after, injection were excluded from the study; thus the study was based on an intention-to-treat analysis. Women who were pregnant or not using adequate contraception were excluded, as were patients who had a history of alcohol or other drug abuse, who had previously experienced an adverse reaction to BoNT-A, or who were being treated with aminoglycoside antibiotics (or other medication affecting neuromuscular transmission), antidepressants, neuroleptics, antiepileptics or anticoagulants. Patients were also excluded if they had severe psychiatric disturbance, a skin disorder at the injection site, a predisposition to bleeding, or an anticipated lack of compliance and cooperation.

\section{Study Design and Treatments}

This randomized, double-blind, placebo-controlled study was carried out from March 2001 until October 2002 in 16 German centers. Patients were randomized to receive one of three treatments: 210 units of Dysport injected into pericranial and cervical muscles, 80 units of Dysport injected into pericranial muscles plus placebo $(0.9 \% \mathrm{NaCl})$ injected into cervical muscles, or placebo injected into both sets of muscles (fig. 1). ${ }^{1}$ Randomization was performed in blocks of two using Rancode (Version 3.6; IDV Datenanalyse und Versuchsplanung, Gauting, Germany), and blinding was ensured by preparation of the injections in a separate room, by a third person, with allocation to treatment groups being noted and placed in sealed envelopes. Injections were performed according to a fixed scheme, with 18 injection sites on the head and neck (table 1). This investigator-initiated trial was conducted in accordance with the Declaration of Helsinki. Approval was obtained from the ethics committee in all facilities that had such a committee, and written informed consent was obtained from each patient before the trial.

\section{Evaluation of Efficacy and Safety}

The study involved six assessments, two prior to treatment (weeks -10 and -4), one at the time of randomization and injection of either active treatment or placebo (week 0 , baseline), and three after the injection (weeks 4,8 and 12). Patients kept a headache diary for the entire 22 weeks, initially for the investigators to assess whether the inclusion criteria were met (weeks -10 to -4 ), and then for a 4 -week baseline phase prior to treatment (week 0). Patients were asked to record each day the incidence, duration and severity of migraine attacks (on a Verbal Rating Scale: $1=$ mild, 2 = moderate, $3=$ severe, $4=$ intolerable), pain intensity $(0=$ no headache, $1=$ mild, $2=$ moderate, 3 = severe headache $)$, occurrence of aura or concomitant symptoms, and acute medication used for treatment of migraine attacks. At the initial visit (week -10) and at week 12, patients filled in Beck's Depression Inventory. At week 12, patients and investigators also had to give a global rating of the treatment efficacy $(1=$ much better, $2=$ slightly better, 3 = unchanged, $4=$ slightly worse, $5=$ much worse). In addition to a physical examination at each study visit, tenderness of cranial and facial muscles was assessed using a Total Tenderness Score [24].

\footnotetext{
1 Note that the dosages given apply only to Dysport. Although BoNTA preparations are formulated as mouse $\mathrm{LD}_{50}$ units, differences in assay methodology between different BoNT-A compounds mean that the units of measurement are not the same. When comparing data between studies, a ratio of between 2 and 3 units of Dysport to 1 unit of Botox ${ }^{\circledR}$ (Allergan, Inc., Irvine, Calif., USA) should be used [21-23].
} 
Table 1. Injection sites and doses per muscle per body side in the group that received 210 units of Dysport ${ }^{1}$

\begin{tabular}{lll}
\hline Muscle & $\begin{array}{l}\text { Injection } \\
\text { sites, } \mathrm{n}\end{array}$ & $\begin{array}{l}\text { Total dose per muscle } \\
\text { (mouse } \mathrm{LD}_{50} \text { units) }\end{array}$ \\
\hline Trapezius & 3 & 45 \\
Splenius capitis & 2 & 20 \\
Temporalis & 2 & 20 \\
Frontalis & 1 & 10 \\
Corrugator & 1 & 10 \\
\hline Total per body side & 9 & 105 \\
\hline
\end{tabular}

$\mathrm{LD}_{50}$ lethal dose expected to cause the death of $50 \%$ of the animal population; standard deviation.

${ }^{1}$ In the 80 units of the Dysport group, only the neck muscles were injected with placebo $(0.9 \% \mathrm{NaCl})$; in the placebo group, all 18 sites were injected with placebo $(0.9 \% \mathrm{NaCl})$.

The primary endpoint was the reduction in the number of migraine attacks during the previous 28 days at week 8 and week 12 compared with the 28 days preceding baseline. A migraine was defined according to the IHS criteria [8], and in the patient diaries, distinct attacks were counted if separated by a 24 -hour headache-free interval [25]. The number of attacks at 8 weeks was calculated as the mean number of attacks between days 28 and 55; the number of attacks at week 12 was the mean number of attacks between days 56 and 84 .

Secondary efficacy measures included: the number of days with migraine; mean headache duration; mean scores for migraine severity and headache intensity from baseline to the target intervals; total attack duration and mean attack duration in hours; use of analgesics; migraine-related disability, and attacks with aura or autonomic concomitant symptoms. Secondary efficacy measures were preplanned in the statistical analysis plan; however, they were analyzed descriptively without adjustment of primary type error. Adverse events were recorded by the physician at three visits after injection (weeks 4,8 and 12).

\section{Power Calculations and Randomization}

To detect a reduction in attacks between baseline and target interval, in favor of verum, two groups of 50 patients were necessary to result in a study power of $80 \%$, assuming one attack less per 28 days on average, and a standard deviation of two attacks and a first type error $\alpha=0.05$ (PASS; NCSS, Inc., Kaysville, Utah, USA; two-sample power analysis adjusted for a Mann-Whitney test assuming a uniform data distribution). Assuming an expected dropout rate of $10-20 \%$ it was therefore planned to include at least 60 patients in each of the Dysport and placebo groups. $\mathrm{Pa}$ tients were randomized to two doses of Dysport for the exploratory analyses.

\section{Statistical Analyses}

The statistical analysis of efficacy was based on all patients who received an injection of Dysport and who had a recorded number of migraine attacks before (weeks -4 to 0 ) and after (weeks 4-12) injection (intention-to-treat analysis). Missing data

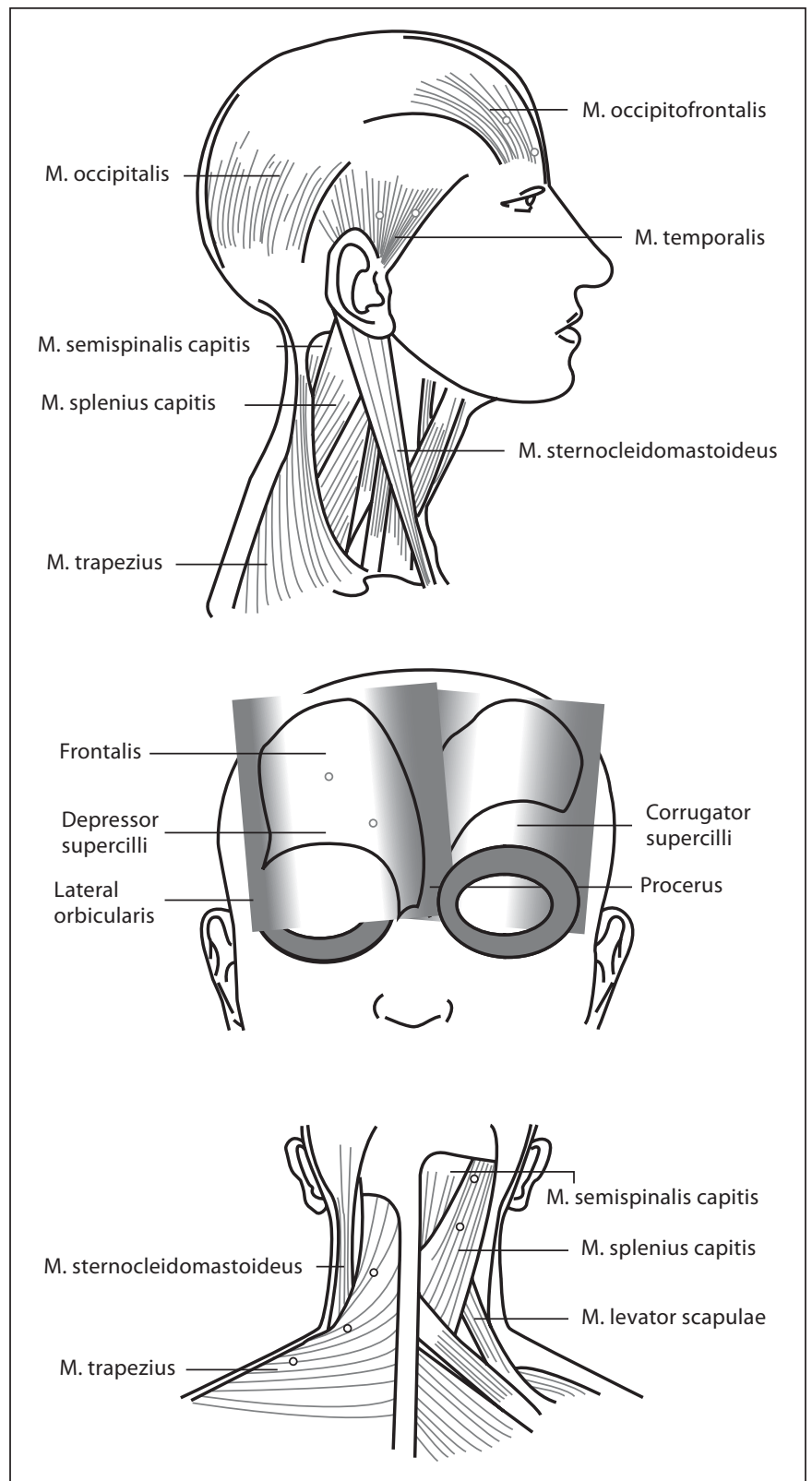

Fig. 1. Position of injection sites in pericranial and cervical muscles.

were replaced by carrying forward the last observation. For the primary efficacy endpoint, the non-parametric Mann-Whitney $U$ test [26] and the Wilcoxon-Mann-Whitney point estimator [27] were used to assess the difference between BoNT-A and placebo, the analysis being performed using a two-group design. The same statistical methods were applied to the secondary efficacy variables, but they were analyzed in a strictly descriptive manner with reference to the primary parameter.

All patients who received study medication were included in the safety analysis. Summary statistics were calculated separately for the number of adverse events. 
Fig. 2. Diagram showing the flow of participants through the study. ITT = Intention-to-treat.

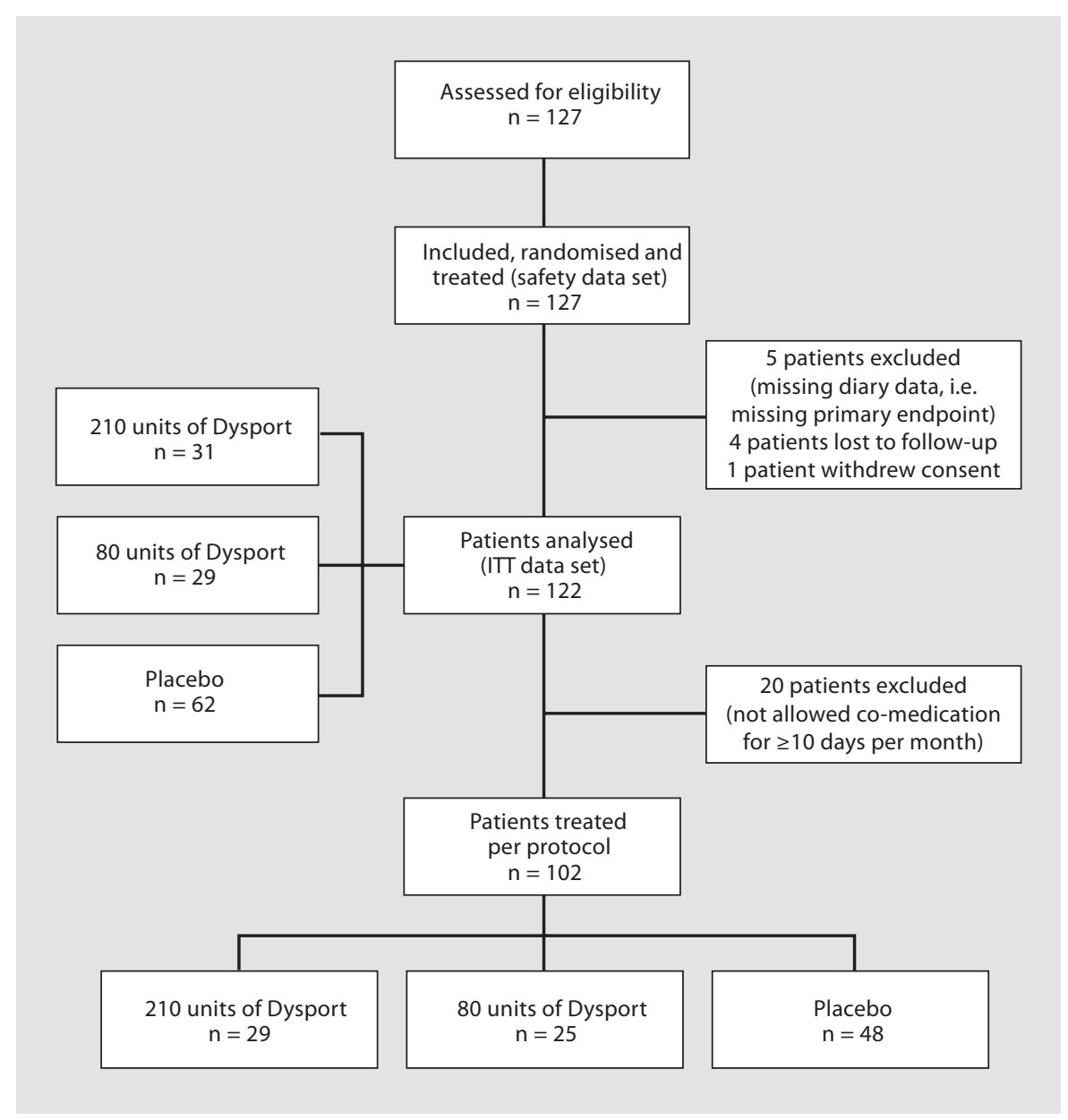

\section{Results}

\section{Patient Disposition and Characteristics}

The safety evaluation was performed on all 127 patients assessed for eligibility and injected with either 210 units of Dysport $(n=32), 80$ units of Dysport $(n=32)$ or placebo $(n=63)$ (fig. 2$)$. In total, $96 \%(n=122)$ could be defined as the intention-to-treat population used for data analysis; 5 patients could not be fully analyzed as their headache diaries were incomplete. The total numbers of patients analyzed were 31 (210-unit group), 29 (80-unit group) and 62 (placebo group). The patients' median age was 46 years (interquartile range: $38-55$ years, i.e., $50 \%$ of subjects were within this age range). The mean age of those in the 210-unit group ( $42 \pm 12$ years), however, was significantly younger than in the two other groups ( $49 \pm$ 11 years for the 80 -unit group, and $47 \pm 12$ years for those in the placebo group) (table 2). Male-to-female ratio was not statistically different among the three groups.
Mean frequency of migraine attacks at baseline in all groups was from 4 to 5 per month with an average duration of $36-40 \mathrm{~h}$ in the three groups.

\section{Treatment Efficacy}

The primary efficacy parameter was the reduction in the number of migraine attacks within 28 days during the second and third 28-day interval after treatment (combined mean of weeks $4-8$ and weeks 8-12) compared with 28 days prior to baseline (weeks $-4-0$ ). Statistical analysis resulted in a mean of 0.54 fewer attacks for patients receiving placebo and 0.94 fewer attacks for those receiving verum (both verum-treated groups pooled). This difference was not statistically significant for either of the treatment groups ( $\mathrm{p}=0.25$; two-sided Mann-Whitney $\mathrm{U}$ test; $\mathrm{p}=0.526 ; 95 \%$ confidence interval, 0.4191 , 0.6330 , respectively).

No differences from baseline to the target intervals occurred among the treatment groups for the secondary ef- 


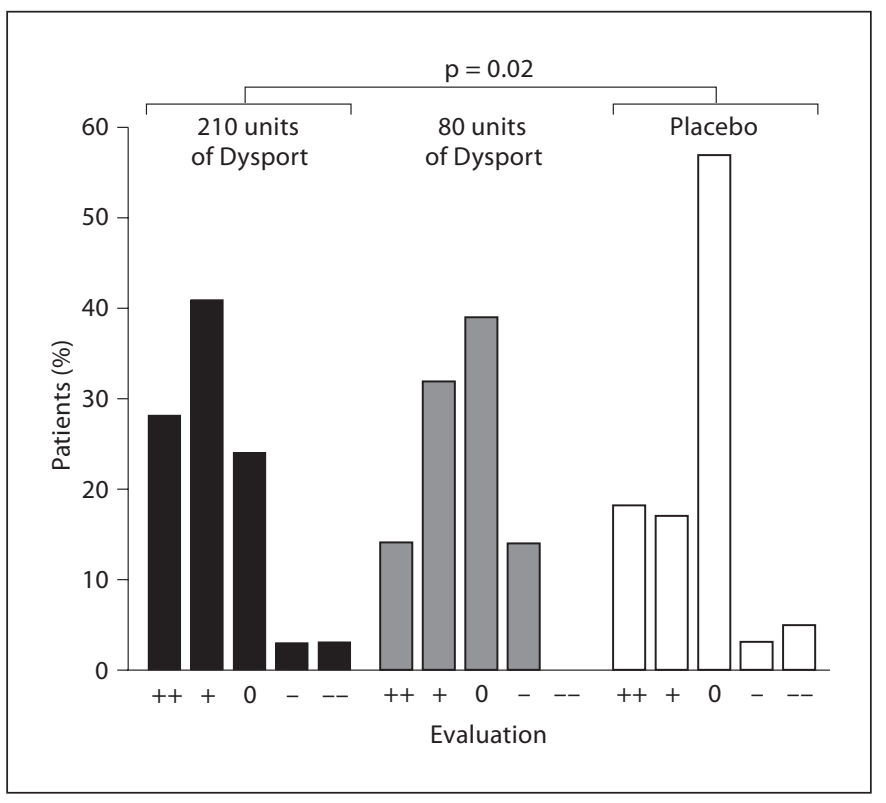

Fig. 3. Patient global evaluation of treatment efficacy. The p value of 0.02 relates to the range of patient evaluations of 210 units of Dysport vs. all patient evaluations of placebo. $++=$ Much better; $+=$ slightly better; $0=$ no change; $-=$ slightly worse; $--=$ much worse.

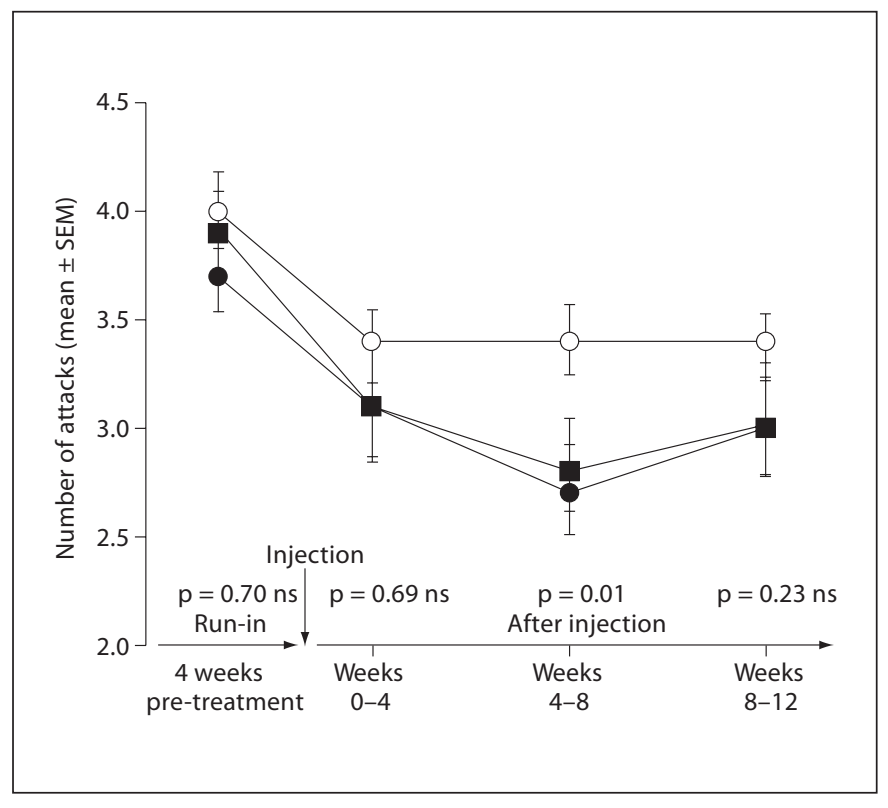

Fig. 4. Comparison of number of migraine attacks (headache-free interval of $48 \mathrm{~h}$ ) at weeks $4-12$ in patients receiving 210 units of Dysport $(\bullet), 80$ units of Dysport $(\mathbf{\square})$ or placebo $(\bigcirc)$. p values represent analysis of pooled Dysport results vs. placebo, analyzed using rank analysis of variance.

Table 2. Patient demographics and baseline migraine characteristics

\begin{tabular}{|c|c|c|c|c|}
\hline & $\begin{array}{l}210 \text { units of } \\
\text { Dysport }(n=31)\end{array}$ & $\begin{array}{l}80 \text { units of } \\
\text { Dysport }(n=29)\end{array}$ & $\begin{array}{l}\text { Placebo } \\
(\mathrm{n}=62)\end{array}$ & $\mathrm{p}$ value \\
\hline \multicolumn{5}{|l|}{ Sex } \\
\hline Male & $7(23 \%)$ & $4(14 \%)$ & $9(15 \%)$ & \\
\hline Female & $24(77 \%)$ & $25(86 \%)$ & $53(85 \%)$ & 0.56 \\
\hline Mean age, years $\pm \mathrm{SD}$ & $42 \pm 12$ & $49 \pm 11$ & $47 \pm 11$ & 0.04 \\
\hline Mean time since first migraine onset, years \pm SD & $23 \pm 14$ & $29 \pm 13$ & $27 \pm 12$ & 0.08 \\
\hline Mean attack frequency per month, $\mathrm{n} \pm \mathrm{SD}$ & $5 \pm 1$ & $4 \pm 1$ & $5 \pm 1$ & 0.41 \\
\hline Mean attack duration for all patients, $\mathrm{h} \pm \mathrm{SD}^{1}$ & $36 \pm 23$ & $37 \pm 20$ & $40 \pm 22$ & 0.51 \\
\hline Mean number of days with analgesics per month, days \pm SD & $7 \pm 3$ & $6 \pm 2$ & $7 \pm 2$ & 0.16 \\
\hline
\end{tabular}

${ }^{1}$ HS, 1988 criteria (the most recent criteria available at the time of the study).

ficacy parameters. Furthermore, Beck's Depression Inventory and the Total Tenderness Score revealed no differences among the three groups. The patients' global evaluation of treatment efficacy, however, was higher in the 210-unit group than in the placebo group: $69 \%(20 / 29)$ of the patients in the 210-unit group recorded their symptoms as slightly or much better and $24 \%(7 / 29)$ as un- changed compared with $35 \%(21 / 60)$ recording slightly or much better and 57\% (34/60) recording unchanged for those in the placebo group ( $\mathrm{p}=0.02)$ (fig. 3). There were no differences among treatment groups with respect to the investigators' global evaluation of efficacy.

The recommended headache-free interval between migraine attacks has not been clearly defined, with rec- 
ommendations citing a 48-hour interval or a separation between attacks of 1 headache-free day (which may be $<48 \mathrm{~h}$ ) according to a patient's headache diary [25]. Therefore, although a 24-hour headache-free interval was preplanned for the study, we also performed post-hoc analyses using a 48-hour headache-free interval to define two separate migraine attacks. For weeks $4-8$, the results showed a pronounced difference in the mean number of migraine attacks experienced by patients in the 210 -unit group (2.7 attacks), patients in the 80 -unit group (2.8 attacks) and patients in the placebo group (3.4 attacks). Pooled analysis showed a descriptive superiority in favor of verum compared with placebo ( $p=0.01$, rank analysis of variance) (fig. 4).

\section{Safety Analyses}

Treatment was generally well tolerated in the $127 \mathrm{pa}-$ tients analyzed for safety. Adverse events occurred in $38 \%(12 / 32)$ and $13 \%(4 / 32)$ of patients in the 210 - and 80 unit groups, respectively, and in $17 \%(11 / 63)$ of patients receiving placebo. The most frequent adverse event was neck weakness in 8 patients (13\%) who received verum and 1 patient $(2 \%)$ receiving placebo $(\mathrm{p}<0.05$, pooled analysis). Ptosis was reported for 2 patients who received verum ( $3 \%$, pooled analysis; 1 patient for each dose).

\section{Discussion}

The difference in treatment efficacy between the two doses of Dysport and placebo was not statistically significant with regard to the primary endpoint (reduction in the number of migraine attacks compared with baseline). Thus, this study did not confirm the findings of several open-label [11-13] and placebo-controlled double-blind trials $[6,14,16,18]$ that reported efficacy of botulinum toxin against migraine severity, the amount of analgesics needed or the occurrence of accompanying symptoms. However, as in the studies by Silberstein et al. [14] and Goebel et al. [6], we saw a trend towards a reduction in the frequency of migraine attacks with verum.

A difference in favor of active treatment was seen in the patients' global evaluation of treatment efficacy for the higher dose of 210 units Dysport. The potency of the two BoNT-A preparations used in different studies should be highlighted. Two to three units of Dysport are approximately equivalent to 1 unit of Botox [28]. Consequently, the lower dose in our study ( 80 units of Dysport) may be considered to be equivalent in potency to the 25 units of Botox used in the Silberstein trial [14]. The patients' pos- itive evaluation of the higher dose in our study is opposed to the results of the Silberstein trial, where only the low dose of BoNT-A was effective, although this may be accounted for by differences in injection sites. In the Silberstein trial, injections were limited to facial muscles [14], whereas in our study the high-dose regimen also included the neck musculature.

In some studies, an explanation of the negative results was the possible influence of allowing headache prophylactic treatment $[29,30]$. The withdrawal of any prophylactic migraine treatment before the baseline period, however, had no positive impact on our study results.

Additional post-hoc analyses using a 48 -hour headache-free interval were carried out due to conflicting definitions of the duration of the headache-free interval between two attacks in the Guidelines for Controlled Trials for Drugs in Migraine, 2000 [25]: 'A migraine attack which is interrupted by sleep, or temporarily remits, and then recurs within $48 \mathrm{~h}$ should be recorded as one attack. A practical solution to differentiating these using diary entries over the previous month is to count as distinct attacks only those that are separated by an entire day headache-free', which corresponds to a 24 -hour interval. Using the 48-hour definition, we found a significant reduction for the patients treated with botulinum toxin in migraine frequency occurring between weeks 4 and 8 after injection. We did, however, not see any influence on migraine severity, the use of acute medication or any associated symptoms. This highlights the importance of precise definitions that are sometimes missing in publications on migraine trials and suggests that the relevant international guidelines need to be clearer in this respect.

Differences in inclusion criteria and methodology among studies may also account for differences in results. Patients in the trial by Goebel et al. [15] experienced both migraine and tension-type headaches, and were included only when they had increased tenderness of pericranial muscles. Furthermore, injections were administered into individually chosen trigger points. Use of a standardized injection scheme, as in our study and that of Evers et al. [19], seems to be less efficient. Also the different distribution of the dose to all pericranial (210 units group) or limited only to the facial muscles ( 80 units group), as in Saper et al. [30], did not have an effect on the headache symptoms.

In most trials, as in ours, a single treatment and a 3month follow-up period are applied. However, Aurora et al. [29] could also not show a positive effect of prophylactic treatment of episodic migraine after multiple treat- 
ments and a follow-the-pain treatment paradigm in predefined muscle areas. Our study did not detect increased sensitivity of head and neck muscles in any patient group, as evaluated by the Total Tenderness Score. A missing effect of BoNT-A treatment on Total Tenderness Scale was also described by Vo et al. [31]. Our patient cohort may not, therefore, seem to be particularly predisposed to migraine caused by muscular trigger factors. The question of whether patients with a particular type of migraine may respond to BoNT-A treatment still needs further clarification. The clear indication of BoNT-A efficacy against migraine frequency observed in our standardized and non-selective approach suggests the need for a more thorough investigation of factors that might predispose patients to a better response to the treatment.

The safety profile of Dysport was good: except for neck weakness, which increased with BoNT-A treatment in the pooled analysis, there were no marked differences in reported adverse events between the groups.

Our study did not demonstrate significant improvement of BoNT-A treatment compared with placebo in reducing the frequency of monthly migraine attacks and hence supports the results of other negative randomized studies in prophylactic headache treatment with botulinum toxin. According to a recent survey on evidencebased medicine on the use of botulinum toxin for headache disorders [32], prospective primary outcome measures are in general not met, although secondary outcomes are positive in some studies. The conclusion states that the treatment effectiveness is considered 'unproven'. However, ongoing and further studies should address the question of whether a specific subset of patients who experience migraine might benefit from BoNT-A treatment.

\section{Acknowledgements}

This study was an investigator-initiated clinical trial supported by Ipsen Pharma, Ettlingen, Germany. Ipsen Pharma supplied BoNT-A (Dysport) but did not design the study, collect, analyze or interpret the data, and did not write any part of this report. Conflict of interest: Dr. Ceballos-Baumann has received honoraria for speeches from Ipsen Pharma and from other companies that manufacture botulinum toxin.

\section{References}

1 Snow BJ, Tsui JK, Bhatt MH, Varelas M, Hashimoto SA, Calne DB: Treatment of spasticity with botulinum toxin: a doubleblind study. Ann Neurol 1990;28:512-515.

2 Annese V, Basciani M, Borrelli O, Leandro G, Simone P, Andriulli A: Intrasphincteric injection of botulinum toxin is effective in long-term treatment of esophageal achalasia. Muscle Nerve 1998;21:1540-1542.

3 Jankovic J, Orman J: Botulinum A toxin for cranial-cervical dystonia: a double-blind, placebo-controlled study. Neurology 1987; 37:616-623.

4 Heckmann M, Ceballos-Baumann AO, Plewig G: Botulinum toxin A for axillary hyperhidrosis (excessive sweating). N Engl J Med 2001;344:488-493.

5 Ashkenazi A, Silberstein SD: Botulinum toxin and other new approaches to migraine therapy. Annu Rev Med 2004;55:505-518.

6 Goebel H: Botulinum toxin in migraine prophylaxis. J Neurol 2004;251(suppl 1):1/8$1 / 11$.

7 Manzoni G, Torelli P: Epidemiology of migraine. J Headache Pain 2003;4(suppl 1):s18s22.
8 Headache Classification Committee of the International Headache Society: Classification and diagnostic criteria for headache disorders, cranial neuralgias and facial pain. Cephalalgia 1988;8(suppl 7):1-96.

9 The International Classification of Headache Disorders, ed 2. Cephalalgia 2004; 24(suppl 1):8-160.

10 Rothrock JR: Botox ${ }^{\circledR}$ for headache treatment. Headache 2007;47:345-346.

11 Mauskop A, Basedo R: Botulinum toxin is an effective prophylactic treatment for migraines (abstract). Cephalalgia 2000;20:422.

12 Smuts HH, Barnard PW: Botulinum toxin in the treatment of headache syndromes: a clinical report on 79 patients. Cephalalgia 2000; 20:332-337.

13 Binder WJ, Brin MF, Blitzer A, Schoenrock L, Diamond B: Botulinum toxin type A (BTX-A) for migraine: an open label assessment. Mov Disord 1989;13(suppl 2):241.

14 Silberstein S, Mathew N, Saper J, Jenkins S, for the Botox Migraine Clinical Research Group: Botulinum toxin type $\mathrm{A}$ as a migraine preventive treatment. Headache 2000; 40:445-450.

15 Goebel H, Heinze A, Zumbroich V, HeinzeKuhn K: Treatment of coexisting migraine and chronic tension-type headache with botulinum toxin A: a double-blind, placebocontrolled study. Cephalalgia 2003;23:690.
16 Brin M, Swope D, O’Brien C, Abbasi S, Pogoda JM: Botox ${ }^{\circledR}$ for migraine: double-blind, placebo-controlled, region-specific evaluation. Cephalalgia 2000;20:421-422.

17 Barrientos N, Chana P: Efficacy and safety of botulinum toxin type $\mathrm{A}\left(\right.$ Botox $\left.^{\circledR}\right)$ in the preventive treatment of migraine. 12th International Headache Seminar, Copenhagen, March 7-9, 2003.

18 Relja MA, Klepac N: Botulinum toxin type A reduces acute medication (triptans) use in migraine patients. Neurology 2003;60: A321.

19 Evers S, Vollmer-Haase J, Schwaag S, Rahmann A, Husstedt IW, Frese A: Botulinum toxin $\mathrm{A}$ in the prophylactic treatment of migraine - a randomized, double-blind, placebo-controlled study. Cephalalgia 2004;24: 838-843.

20 Evers S: Status on the use of botulinum toxin for headache disorders. Curr Opin Neurol 2006;19:310-315.

21 Sampaio C, Costa J, Ferreira JJ: Clinical comparability of marketed formulations of botulinum toxin. Mov Disord 2004;19(suppl 8): S129-S136.

22 Guttman C: Equipotent doses of botulinum toxin type A products share same radius of action. Dermatology Times, September 1, 2005, p 66. 
23 Wegner F, Schwandt I, Gelbrich G, Wagner A, Bogdahn U, Schulte-Mattler WJ, Wohlfarth K: Pharmacokinetic properties of different preparations of botulinum neurotoxin type A; in Advancing Research and Improving Care. 5th International Conferences on Basic and Therapeutic Aspects of Botulinum and Tetanus Toxins, Denver 2005.

24 Tfelt-Hansen P, Lous I, Olesen J: Prevalence and significance of muscle tenderness during common migraine attacks. Headache 1981;21:49-54.

25 International Headache Society Clinical Trials Subcommittee; Tfelt-Hansen P, Block G, Dahlof C, Diener H-C, Ferrari MD, Goadsby PJ, Guidetti V, Jones B, Lipton RB, Massiou H, Meinert C, Sandrini G, Steiner T, Winter PBO: Guidelines for controlled trials of drugs in migraine, ed 2. Cephalalgia 2000; 20:765-786.
26 Lehmann EL: Nonparametrics. Statistical Methods Based on Ranks. Englewood Cliffs, Prentice-Hall, 1998.

27 Wei L, Lachin J: Two-sample asymptotically distribution-free tests for incomplete multivariate observations. J Am Statist Assoc 1984;79:653-661.

28 Ranoux D, Gury C, Fondarai J, Mas JL, Zuber M: Respective potencies of Botox ${ }^{\circledR}$ and Dysport $^{\circledR}$ : a double-blind, randomised, crossover study in cervical dystonia. J Neurol Neurosurg Psychiatry 2002;72:459462.

29 Aurora SK, Gawel M, Brandes JL, Pokta S, Vandenburgh AM; Botox North American Episodic Migraine Study Group: Botulinum toxin type a prophylactic treatment of episodic migraine: a randomized, double-blind, placebo-controlled exploratory study. Headache 2007;47:486-499.
30 Saper JR, Mathew NT, Loder EW, DeGryse R, VanDenburgh AM, BoNTA-009 Study Group: A double-blind, randomized, placebo-controlled comparison of botulinum toxin type A injection sites and doses in the prevention of episodic migraine. Pain Med 2007;8:478-485.

31 Vo AH, Satori R, Jabbari B, Green J, Killgore WD, Labutta R, Campbell WW: Botulinum toxin type $\mathrm{A}$ in the prevention of migraine: a double-blind controlled trial. Aviat Space Environ Med 2007;78(suppl):B113-B118.

32 Schulte-Mattler WJ, Leinisch E: Evidencebased medicine on the use of botulinum toxin for headache disorders. J Neural Transm 2008;115:647-651. 